\title{
Combination of fixative agents and fixation times to visually differentiate the cortical from the medullary layer in bovine adrenal glands
}

\author{
FABRÍCIO S. OLIVEIRA ${ }^{1}$, FERNANDA MACITELLI ${ }^{2}$, CAIO C.C. SANTOS ${ }^{1}$, JANAINA S. BRAGA ${ }^{3}$, \\ BARBARA C. COSTA ${ }^{1}$, MARINA PASTORE ${ }^{1}$, THIAGO A.S.S. ROCHA ${ }^{1}$ and MATEUS J.R.P. DA COSTA ${ }^{3}$ \\ ${ }^{1}$ Laboratório de Anatomia Cirúrgica, Departamento de Morfologia e Fisiologia Animal, \\ Faculdade de Ciências Agrárias e Veterinárias, Universidade Estadual Paulista/UNESP, Via \\ de acesso Paulo Donato Castelane, s/n, 14884-900 Jaboticabal, SP, Brazil \\ ${ }^{2}$ Instituto de Ciências Agrárias e Tecnológicas, Universidade Federal do Mato Grosso/ \\ UFMT, Avenida dos Estudantes, 5055, 78735-910 Rondonópolis, MT, Brazil \\ ${ }^{3}$ Departamento de Zootecnia, Faculdade de Ciências Agrárias e Veterinárias, Universidade Estadual \\ Paulista/UNESP, Via de acesso Paulo Donato Castelane, s/n, 14884-900 Jaboticabal, SP, Brazil \\ Manuscript received on May 14, 2018; accepted for publication on July 2, 2018
}

\begin{abstract}
Chronic stress exposure commonly increases adrenals weight and changes their morphology. This study aimed to compare four methods to delimitate the cortical and medullary layers of adrenals glands in Nelore bulls. Fresh adrenals did not present differentiation between layers. Then, frozen adrenals were distributed in plastics bags with fixative Bouin (G1), $96^{\circ} \mathrm{GL}$ ethylic alcohol (G2), 10\% formaldehyde (G3), or 2.5\% glutaraldehyde (G4). After 12 hours of fixation, the G1 adrenal glands did not show the entire cortical layer marked by Bouin's solution. For G2 and G3 there was a poor contrast, while for G4 there was a reasonable contrast. After 24 hours of fixation, G1 had an excellent contrast between layers, while G2 and G4 had a reasonable contrast and G3 a very bad contrast. After 48 hours it was difficult to differentiate cortical and medullar layers for G1; for Group 2 we get a reasonable contrast; and for G3 the contrast was bad. For G4 the contrast was not as sharp due to the medulla became dark. It was concluded that fixation of adrenals must be done in Bouin's solution for 24 hours to obtain an effective evaluation of the adrenals' morphometry.
\end{abstract}

Key words: animal welfare, morphometry, stress, anatomy, gland.

\section{INTRODUCTION}

An animal can be considered in a state of stress when it shows extreme changes in its neuroendocrine, physiological and behavioral responses to cope with adverse aspects of its environment (Fraser et al. 1975), as an attempt to maintain or restore its

Correspondence to: Fabrício Singaretti de Oliveira

E-mail: singaretti@fcav.unesp.br homeostatic balance (Von Borel 1995), and the adrenal glands have an important role in this process.

Cattle adrenal glands are asymmetric and elongated (Dyce et al. 2010), being located on each side of the median plane (next to the cranial end) of the kidneys, without any functional relationship with them (König and Liebich 2011), and the right glands present a V-shape and the left, C-shape (Venzke 1986). 
The adrenal glands are relatively bigger in wild species than in domestic ones, as well as in young individuals when compared to adults, and in pregnant and lactating females than those reproductively inactive (Dyce et al. 2010). It has been also described that morphological changes, such as hypertrophy, occur in adrenal glands of animals subjected to situations of prolonged stress (Ulrich-Lay et al. 2006). Thus, the chronic stress seems to affect directly the size and weight of the adrenal glands. For example, adrenal glands of Wistar rats subjected to inoculation of tumor cells of the Walker-256 carcinosarcoma showed, after 12 days, larger cortical area and weight when compared to the control group, but did not show any difference in the size of the medullary area (Fonseca et al. 2009).

Additionally, it is well known that the adrenal gland hypertrophy is directly associated with high concentration of cortisol (Howes et al. 1960, Doornenbal 1974); for example, in cattle it can increases from 4 to 13 times in relation to the basal level when the animals are facing stressful situations (Boissy and Le Neindre 1997). Thus, the morphometry of the adrenal glands has a potential to be used as an indicator of stress in this species.

The objective of this study was to evaluate the efficiency of four fixative agents (a Bouin's solution, ethyl alcohol, formaldehyde and glutaraldehyde) and three fixation times (12, 24 and 48 hours) that allow to differentiate the cortical from the medullary area in the adrenal glands of beef cattle, making possible to use their measurements as indicators of cattle welfare.

\section{MATERIALS AND METHODS}

The study was conducted using 58 adrenal glands from Nellore bulls raised on pasture and finished in feedlot. The adrenal glands were removed during the carcasses evisceration in a commercial slaughterhouse, being immediately dissected, weighed and refrigerated at $4^{\circ} \mathrm{C}$ during 24 hours.

The glands were then sent to the Department of Animal Morphology and Physiology of the Universidade Estadual Paulista (UNESP), campus Jaboticabal, São Paulo, Brazil, where all the preparations and trials were carried out. Firstly, 10 adrenals glands were defrosted and then cut lengthwise using a scalper to evaluate the possibility of visual differentiation between the cortical and medullary areas. But, it was not possible to differentiate the areas. Then, 48 frozen adrenals glands were randomly and equally distributed in four groups (12 glands in each), they were inserted in $100 \mathrm{ml}$ plastic recipients, filled with one of the following solutions: fixative Bouin (G1) (Synth, Diadema, São Paulo, Brazil), 96 ${ }^{\circ} \mathrm{GL}$ ethylic alcohol (G2) (Synth, Diadema, São Paulo, Brazil), $10.0 \%$ formaldehyde in Phosphate-buffered saline solution (G3) (Synth, Diadema, São Paulo, Brazil) or $2.5 \%$ glutaraldehyde in Phosphate-buffered saline solution (G4) (Synth, Diadema, São Paulo, Brazil); keeping them dipped into these solutions for 12, 24 or 48 hours at room temperature (4 glands per time). The final combination resulted in four adrenal glands per solution per fixation time. Those fixative agents were chosen due their availability in animal anatomy and histology laboratories.

After these procedures all glands, in the respective times, were removed from the solutions, dried in paper towels, cut lengthwise and placed individually on a clear plane surface. All samples were identified and then photographed three times with a digital camera supported on a tripod (Sony W110 7.2 Megapixel), maintaining the lens parallel to the surface. The images were evaluated using the Image J software (https://imagej.nih.gov/ij), being classified as poor (no contrast between the cortical and medullary areas), reasonable (moderate contrast between areas) or excellent (total differentiation between areas). 
All husbandry and experimental procedures were approved by the institutional ethics committee (process number 25961/13).

\section{RESULTS AND DISCUSSION}

All fixative agents used in the present study avoided tissue maceration or autolysis, assuring the firm texture (Rodrigues 2010) and the preservation of the adrenal glands layers, which, in conjunction, favored the longitudinal cut of the glands. Additionally, the efficiency of the fixative agents was also confirmed by the absence of visible proliferation of pathogens in samples, not exposing the evaluators to biological risks. It is important to point out that the adrenal glands were entirely fixed for anatomical assessment of the cortical and medullary area, despite of the recommendation of using small fragments for the immersion in the fixative solutions, due to delay for their dissemination within the tissues (Junqueira and Carneiro 2008).

After 12 hours of fixation, the G1 adrenal glands did not show the entire cortical area fixed by Bouin's solution, although there was a contrast between it and the medullar area; G2 and G3 had a poor contrast; and G4 showed a reasonable contrast. The contrasts of G1 and G2 improved after 24 hours of fixation, being classified as excellent and reasonable, respectively; while G3 and G4 maintained the same contrast class observed when using 12 hours of fixation. After 48 hours of fixation in G1 the medullar areas of the adrenal glands were also fixed, making difficult to differentiate it from the cortical area, since both were yellowish; for G2 and G3 the contrast classes did not change, remaining reasonable and poor, respectively; and for G4 the contrast was not as sharp due to the medullary area became dark. These conditions are illustrated in the Figures 1 to 3. The Bouin's solution did not change the tissues morphology after fixation (Gartner and Hiatt 2007, Bacha Junior and Bacha 2003) and made it easier
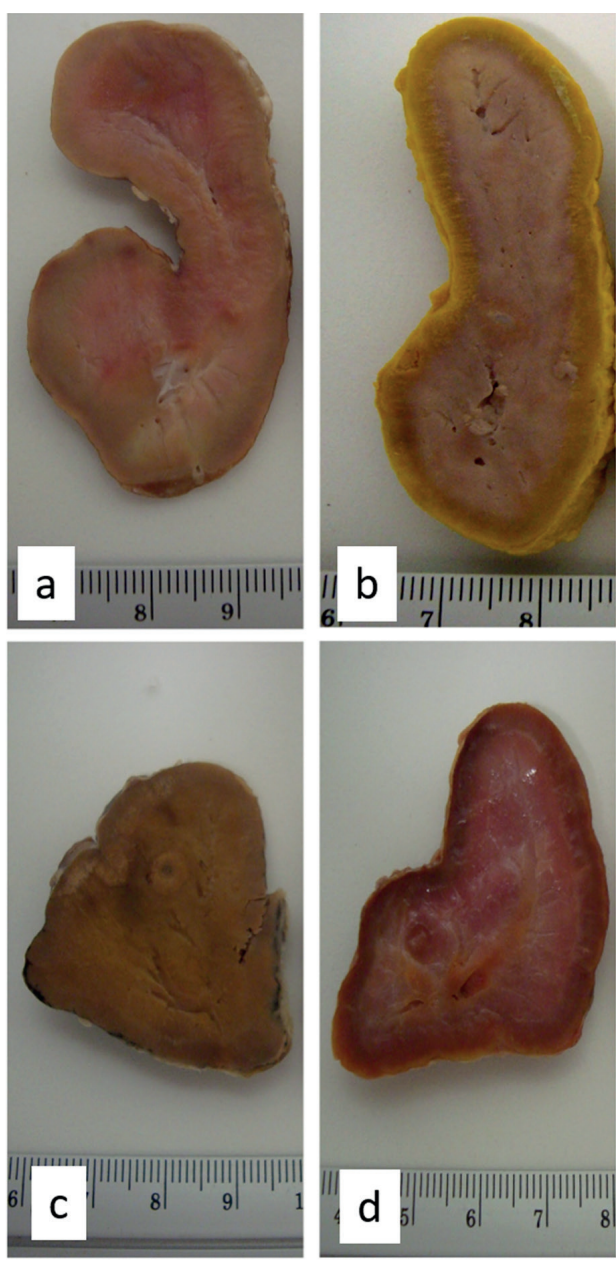

Figure 1 - After 12 hours of fixation with ethylic alcohol (a), Bouin's solution (b), formaldehyde (c) and glutaraldehyde (d), the adrenal glands did not show the entire cortical layer in $\mathbf{b}$. For $\mathbf{a}$ and $\mathbf{c}$ there was a poor contrast, while for $\mathbf{d}$ there was a reasonable contrast.

the visual differentiation of cortical and medullary areas of the adrenal glands.

In spite of ethyl alcohol being classified as a fixative coagulant and characterized by causing tissue morphological alteration (Banks 1991), it was not observed any change in the adrenal glands used in the present study. The ethyl alcohol was the fixative agent of slower tissue penetration, if compared to the other fixative agents evaluated, but provoked muscle stiffness sufficient to allow the longitudinal cut of the adrenal glands, as well as reported in the muscle tissue of bird kept for up to 12 months in this fixative agent (Nunes et al. 2011). 

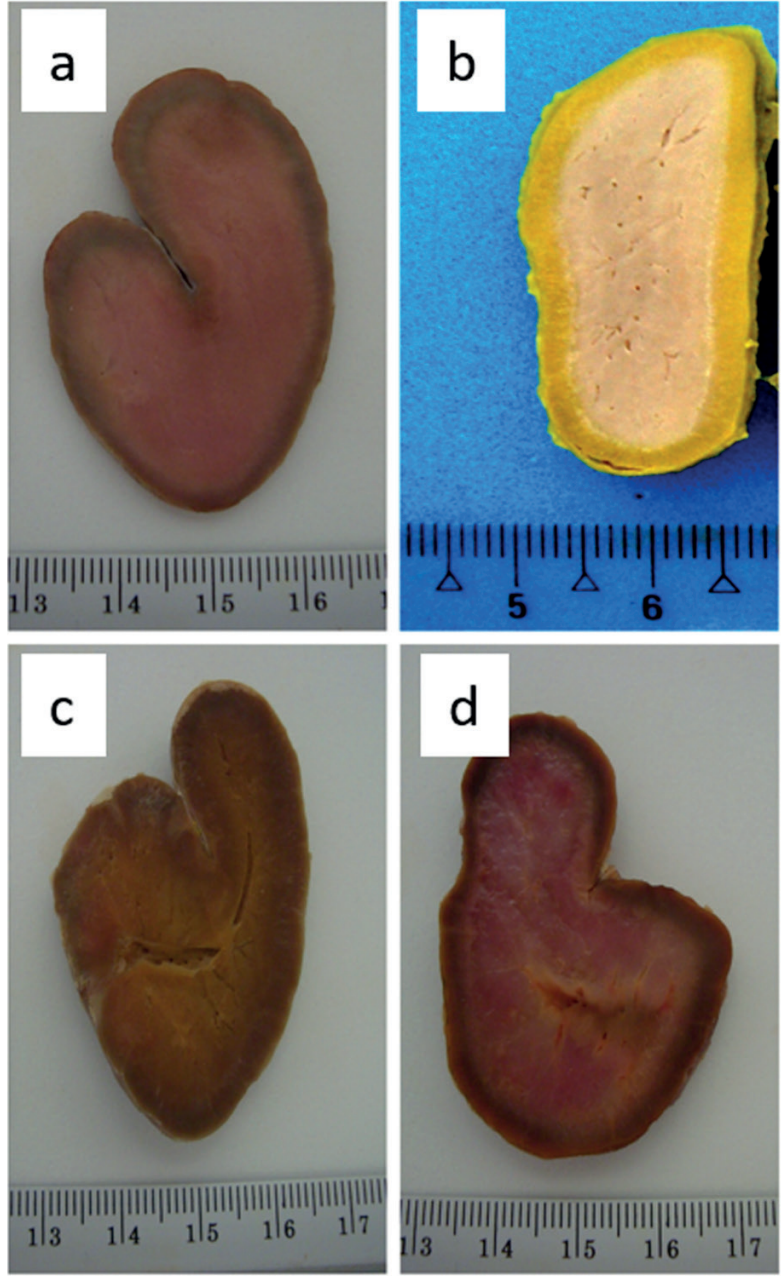

Figure 2 - After 24 hours of fixation with ethylic alcohol (a), Bouin's solution (b), formaldehyde (c) and glutaraldehyde (d), b had an excellent contrast between the layers, while a and d had a reasonable contrast and $\mathbf{c}$ a poor.

The diffusion of the fixative agents by adrenal tissue showed more quickly when formaldehyde was used, the most common fixative agent used in anatomy laboratories in Brazil and that penetrates approximately six millimeters in 12 hours in the tissues (Rodrigues 2010). The formaldehyde, as well as the glutaraldehyde, classified as fixative additive agents, react in the same way as the amine groups (NH2) of tissue proteins and do not induce significant histological changes (Banks 1991, Junqueira and Carneiro 2008). The adrenal glands fixed by these reagents showed similar results regarding the change in coloration, being possible
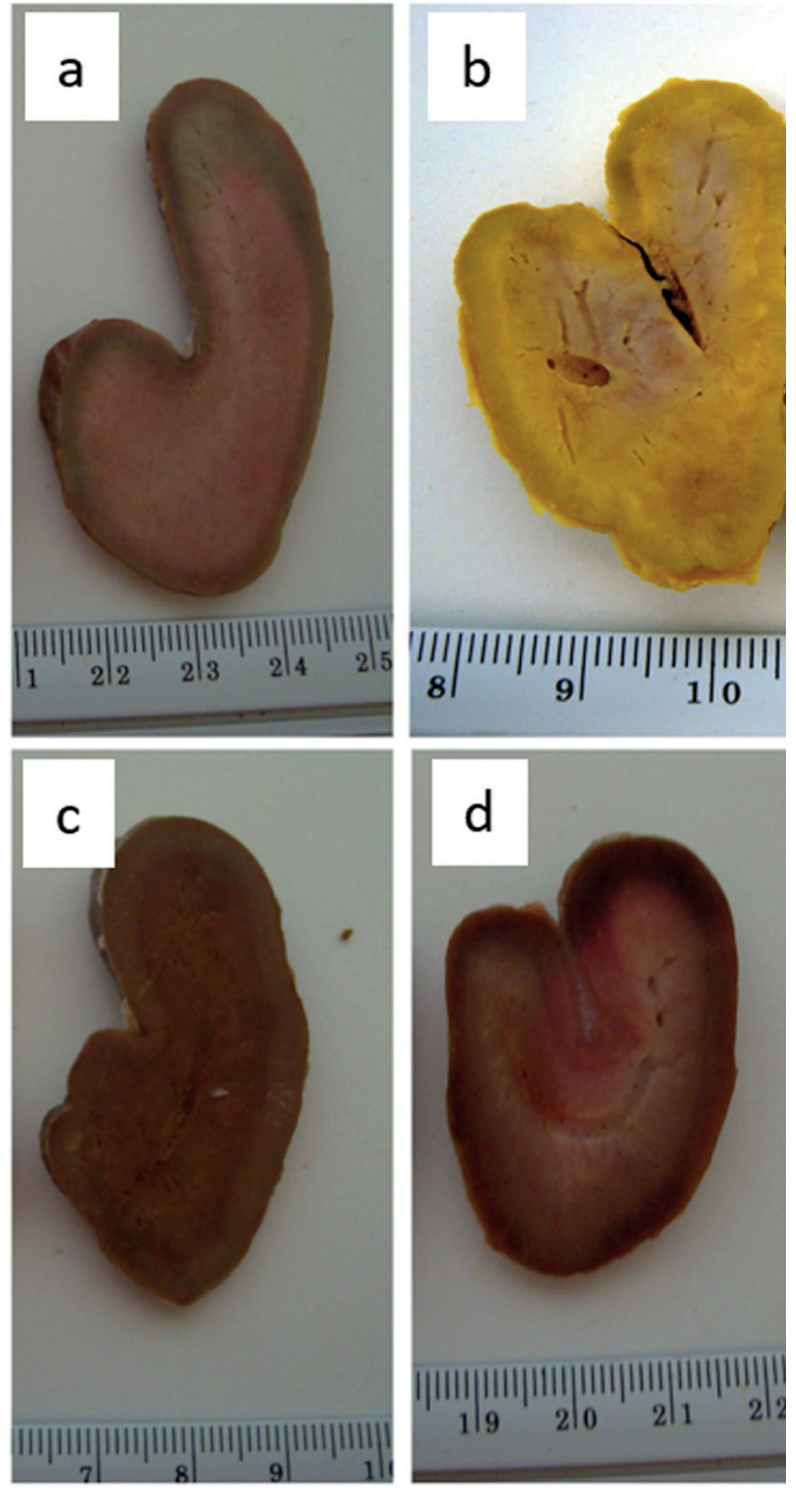

Figure 3 - After 48 hours of fixation with ethylic alcohol (a), Bouin's solution (b), formaldehyde (c) and glutaraldehyde (d), it was difficult to differentiate cortical and medullar layers for b because both were yellowish; for a there was a reasonable contrast; and for $\mathbf{c}$ the contrast was poor. For $\mathbf{d}$ the contrast was not as sharp due to the medulla became dark.

to observe great darkening of the medullary and cortical areas, which hindered the differentiation of the areas.

\section{CONCLUSIONS}

Based in these results we conclude that the fixation of adrenal glands must be done in Bouin's solution 
for 24 hours to obtain an effective evaluation of the adrenal glands areas morphometry.

\section{ACKNOWLEDGMENTS}

We acknowledge the Fundação de Amparo à Pesquisa do Estado de São Paulo (FAPESP) (processes 2014/10317-4, 2014/10251-3 and 2015/06353-8) and the Conselho Nacional de Desenvolvimento Científico e Tecnológico (CNPq) (proc. 483443/2013-1) for the financial support.

\section{REFERENCES}

BACHA JUNIOR WJ AND BACHA LM. 2003. Atlas colorido de histologia veterinária. $2^{\mathrm{a}}$ ed. São Paulo: Roca, 457 p.

BANKS WJ. 1991. Histologia veterinária aplicada. São Paulo: Manole, $629 \mathrm{p}$.

BOISSY A AND LE NEINDRE P. 1997. Behavioral, cardiac and cortisol responses to brief peer separation and reunion in cattle. Physiol Behav 61: 693-699.

DOORNENBAL H. 1974. Endocrine gland and brain weights of market weight bulls and steers representing the shorthorn breed and several breed crosses. Can J Comp Med 38: 417-424.

DYCE KM, SACK W AND WENSING CJG. 2010. Tratado de Anatomia Veterinária. Rio de Janeiro: Elsevier, p. 216 222.

FONSECA EAI, MACIOSZEK MA, SAITO AY, COTRIM KG AND MAZZUCO TL. 2009. Estudo das alterações morfológicas da glândula adrenal na caquexia neoplásica. Semina: Cien Biol Saúde 30: 163-174.

FRASER DJ, RITCHIE JSD AND FRASER AF. 1975. The term "stress" in a veterinary context. Brit Vet J 131: 653662.

GARTNER LP AND HIATT JL. 2007. Tratado de Histologia em Cores. Rio de Janeiro: Elsevier, 576 p.

HOWES JR, HENTGES JF AND WARNICK AC. 1960. Adrenal gland weights of Hereford and Brahman cattle. Proc Soc Exp Biol Med 104: 322-324.

JUNQUEIRA LC AND CARNEIRO J. 2008. Histologia básica. $11^{\mathrm{a}}$ ed., Rio de Janeiro: Guanabara Koogan, 524 p.

KÖNIG HE AND LIEBICH HG. 2011. Anatomia dos animais domésticos. Porto Alegre: Artmed, p. 581-590.

NUNES TC, OLIVEIRA FS, GAMON THM, GUASTALLI BHL, CARMO LG AND DEL QUIQUI EM. 2011. Análise da textura de músculos peitorais submetidos à fixação e conservação em álcool. Braz J Vet Res An Sci 48: 464-467.

RODRIGUES H. 2010. Técnicas Anatômicas. Vitória: GM Gráfica Editora, 269 p.

ULRICH-LAI YM, FIGUEIREDO HF, OSTRANDER MM, CHOI DC, ENGELAND WC AND HERMAN JP. 2006. Chronic stress induces adrenal hyperplasia and hypertrophy in a subregion-specific manner. Am J Physiol - Endocrin Metabol 291: 965-973.

VENZKE WB. 1986. Endocrinologia geral. In: Getty R, Rosembaum CE, Ghoshalo NG and Hillmann D (Eds), Anatomia dos Animais Domésticos de Sisson e Grossman. Rio de Janeiro: Guanabara Koogan, p. 140-152.

VON BOREL E. 1995. Neuroendocrine integration of stress and significance of stress for the performance of farm animals. Appl An Behav Sci 44: 219-227. 